\title{
Efektifitas Penyelenggaraan E-Puskesmas Di Puskesmas Lubuk Buaya Kota Padang
}

\author{
${ }^{1}$ Shilvia Apriyani Putri, ${ }^{2}$ Syamsir \\ ${ }^{1}$ Jurusan Ilmu Administrasi Negara, Fakultas Ilmu Sosial, Universitas Negeri Padang \\ Email: syamsirsaili@yahoo.com, shilviaapriyaniputri07@yahoo.com
}

\begin{abstract}
Abstrak. This research was done in Puskesmas Lubuk Buaya Padang City whichpurpose to discover about to effectiveness of organized e-puskesmas in Puskesmas Lubuk Buaya Padang City. This research applies a descriptive qualitative method, namely a method by providing a comprehensive description of the research. Informants selection of informants in this reseacrhusing purposive sampling technique. Prosess of aggregation data colth pass through observation technique, study documentation and interviews, while technique for validity testing data that using resource triangulation with data analysis such as a data collection, data reduction, data presentation, along with pulling conclusions. The results of the research conducted by researchers was explain effectiveness of organized e-puskesmas in puskesmas Lubuk Buaya Padang City was not yet effective, because in case still presence obstacle inside administration that e-puskesmas, that epuskesmas namely network problems are not always good, sometimes disconnected when used so that it can slow down patient services in medical treatment, and other obstacles, sometimes the patient data input report for each clinic is also done manually till case mentioned needed much time in data in data input medical patient and be able pulling conclusion its not yet effective organized epuskesmas in that Lubuk Buaya.
\end{abstract}

Kata kunci: Effectiveness, E-Government, E-Puskesmas

\section{PENDAHULUAN}

Membicarakan mengenai globalisasi dalam kehidupan selalu tidak bisa kita elakan, suka maupun tidak, siap atau tidaknya, globalisasi selalu masuk ke dalam kehidupan secara menyeluruh ataupun sebagian besar di kehidupan umat manusia di seluruh dunia. Kemajuan di bidang teknologi informasi, komunikasi, komputasi, dan transportasi yang sudah berjalan begitu pesat pada saat ini, sehingga bisa menciptakan sebuah keadaan, globalisasi pada dahulunya selalu membatasi hubungan antar individu, bangsa dan negara dan sekarang makna globalisasi semakin meluas. Kemajuan teknologi informasi sudah membuat hubungan semakin intensif dan cepat, meningkat secara drastis dan biaya yang lebih ekonomis, sehingga bisa menciptakan sebuah keadaan, globalisasi pada dahulunya selalu membatasi hubungan antar individu, bangsa dan negara dan sekarang makna globalisasi semakin meluas.(Irawan, 2013).

Kemajuan teknologi, informasi dan komunikasi (TIK) ialah salah satu faktor pendorong untuk perubahan dan kemajuan perdagangan dunia. Saat ini, informasi diartikan suatu hal yang mengandung nilai ekonomi tinggi hal ini disebabkan karena tidak seluruh kelompok mampu dan berhasil untuk mengolah data mentah menjadi suatu informasi yang cocok bersama keperluannya. TIK merupakan peranan utama untuk mendukung kehidupan sehari - hari, terutama di bidang kesehatan. (Rosadi, 2016)

Penggunaan teknologi informasi pada bidang kesehatan di Indonesia dimuat dalam UU 36 Tahun 2009 yaitu mengenai kesehatan kesehatan, yang bertujuan untuk melaksanakan upaya di bidang kesehatan secara berdaya guna dan praktis maka melalui system teknologi informasi dan lintas sektor. Di Indonesia penerapan E-Health telah mulai diterapkan, yaitu dengan metode kerjasama antar instasni seperti rumah sakit, kampus negeri maupun swasta dan pengadaan bisnis telekomunikasi. Sebagian besar rumah sakit di instansi telah sedari mengaplikasikan teknologi informasi, namun sedang 
dipergunakan pada kepentingan rumah sakit itu sendiri. (Kristianto,2013).

E-Government menurut Bank Dunia (World Bank) ialah penerapan teknologi informasi yang digunakan oleh aparat pemerintah bertujuan agar mampu menyempurnakan silaturrahmi negara antar warga negara, tokoh bisnis maupun sesama pemerintah. Peranan teknologi informasi sangat penting dalam proses pemerintahan mampu meningkatkan kinerja yang terkait dengan aktifitas koordinasi, komunikasi dan termasuk aktifitas pelayanan (Indrajit, 2006).

Tujuan pelaksanaan e-government, berdasarkan hasil riset dan tinjauan dari Harvard JFK School of Government dalam untuk memakai konsep-konsep digitalisasi pada sector public.

$\begin{array}{ccc}\text { Pusat } & \begin{array}{c}\text { kesehatan } \\ \text { merupakan }\end{array} & \begin{array}{r}\text { masyarakat } \\ \text { organisasi }\end{array}\end{array}$ kesehatan yang bergerak membantu fungsi rumah sakit di daerah namun belum bisa terjangkau oleh pelayanan yang dilakukan oleh rumah sakit, bertujuan untuk selalu meningkatkan kualitas pelayanan terhadap masyarakat, salah satunya dengan membangun layanan teknologi informasi dan komunikasi.(Harsiti,2016).

Robbins dalam (Indrawijaya 2010:175) mendefinisikan efektivitas sebagai hatap pengembangan perolehan tujuan organisasi dalam waktu pendek maupun panjang. Pemilihan cara dan langkah tersebut mencerminkan faktor penting, untuk meningkatka kemauan dalam hal menilai, dan pengembangan tujuan organisasi di kehidupan. Sedangkan pendapat Steers, Richard dalam (Sutrisno.2010:123), dasarnya efektivitas dihubungkan bersama tujuan organisasi, seperti keuntungan yang selalu mengabaikan sumber daya manusia sebagai faktor terpenting dalam suatu organisasi. Sedikit berbeda dengan Gitosudarmo dalam (Sutrisno.2010:143) mengartikan efektivitas ialah tujuan sebuah organisasi didasarkan pada sebuah ide, mekanisme, dan peluang.

Efektivitas ialah komponen utama dalam mencapai target dan tujuan yang telah diputuskan dalam tiap organisasi, tindakan ataupun agenda. Efektif jika terpenuhi tujuan atau sasaran seperti yang dikutip Soewarno, Handayaningrat S. (1994:16) menyatakan “ Efektivitas ialah evaluasi dalam makna terwujudnya tujuan yang telah diputuskan.

E-Puskesmas ialah aplikasi untuk pelayanan kesehatan yang diperbaharui dengan tujuan memberikan pelayanan umum kepada masyarakat. Aplikasi ini adalah komponen rancangan dari Smart City yang dikembangkan oleh pemerintah kota Padang dengan kerjasama bersama PT. Telkom. Bersama adanya aplikasi ini, kegiatan pembukuan dan kodifikasi pasien dapat dikerjakan berbasis kmputer serta mempermudah Dinas Kesehatan untuk mengawasi data kesehatan pasien. Aplikasi tersebut bagian penerapan berdasarkan sistem informasi dan komunikasi juga mampu menyerahkan andil sangat banyak dalam mempersembahkan bantuan pertama pada pasien. (Satriadi.2019)

Aplikasi ini merupakan proses dari jalan keluar modernisasi jasa dan bisnis terhadap pasien Puskesmas. Bersama adanya aplikasi tersebut diimpikan layanan yang ada berubah kian pesat serta praktis bersama patokan peliputan data melalui metode dan ketangkasan dalam tahap peliputan terintegrasi dapat dilakukan dengan sangat mudah. (Nur.2015).

Berdasarkan dari pengamatan peneliti pada saat melakukan observasi awal di Puskesmas Lubuk Buaya, aplikasi ini sudah berjalan pada pada beberapa layanan seperti melakukan pelayanan di rekam medik, poli dan apotik, tetapi penggunaan aplikasi tersebut belum efektif karena masih ditemukan kendala dengan gangguan konektivitas internet sehingga hal itu menghambat dalam menginput data pelayanan.

Berdasarkan pemaparan narasumber ibuk X selaku pegawai puskesmas Lubuk Buaya Kota Padang) tanggal 22 Januari 2020, menjelaskan bahwa:

"Aplikasi E-puskesmas diterapkan hampir pada seluruh layanan yang ada di Puskesmas Lubuk Buaya ini, terutama di BP UMUM, Lansia, anak, poli ibu hamil, apotik, dan juga kasir 
serta IGD sudah ada di aplikasi tersebut. E-puskesmas telah diterapkan di Puskesmas Lubuk Buaya ini pada awal tahun 2016 dan sekarang telah di perbaharui menjadi E-Puskesmas Next Generation (E-Puskesmas NG) pada tahun 2019. Aplikasi E-Puskesmas ini berbasis online, sehingga dapat meningkatkan efektifitas layanan kesehatan yang disediakan dan meminimalisir prosedur-prosedur manual'. bahwa :

Lebih lanjut di jelaskan oleh Ibuk $\mathrm{N}$

"Salah satu kesulitan yang ditemui dalam mengoperasionalkan EPuskesmas terdapat dalam item menu pendaftaran yang berbeda dari versi sebelumnya, seperti pada saat selesai mendaftarkan satu orang pasien, kembali lagi ke item menu awal sedangkan versi sebelumnya tidak seperti itu. Hal ini juga terjadi pada bidang pelayanan lainnya sehingga memakan waktu yang cukup lama dan dalam mengoperasionalkan aplikasi tersebut pada saat memberikan layanan kesehatan kepada masyarakat. Masalah lainnya juga terjadi pada koneksi server, sering kali terjadi gangguan server padahal E-Puskesmas sudah dibawah Kominfo yang mengelola, dan juga Kominfo telah bekerja sama dengan Telkom tapi masih saja sering terjadi gangguan server yang menghambat layanan E-Health Service (E-Puskesmas). Di samping fitur-fitur dari E-Puskesmas, ternyata Rekam Medik belum bisa di pergunakan karna legalitas PerMenKesnya belum ada, menimbang nanti adanya kekhawatiran kehilangan Rekam Medik Pasien akibat aplikasi/server E-Puskesmas rusak maupun error."

Berhubungan dengan fenomena di atas, untuk itu penerapan e-puskesmas harus ditingkatkan kualitasnya untuk menyediakan serta menyelenggarakan pelayanan publik kepada masyarakat, oleh sebab itu peneliti sangat tertarik dan berkeinginan untuk mengadakan penelitian serta pengamatan mengenai "Efektifitas Penyelenggaraan EPuskesmas di Puskesmas Lubuk Buaya Kota Padang".

Berdasarkan permasalahan yang dijelaskan sebelumnya, maka rumusan masalah yang sesuai dengan temuan dalam penelitian ini ialah: a) Bagaimanakah penyelenggaraan efektifitas e-Puskesmas di Puskesmas Lubuk Buaya Kota Padang? b) Apa faktor yang mempengaruhi efektifitas penyelenggaraan efektifitas e-puskesmas? Tujuan penelitian untuk mengidentifikasi efektifitas penyelenggaraan e-Puskesmas di Puskesmas Lubuk Buaya Kota Padang dan mengetahui faktor yang mempengaruhi efektifitas e-puskesmas tersebut.

\section{METODE PENELITIAN}

Dalam penelitian ini peneliti menerapkan metode kualitatif. Tempat penelitian adalah di Puskesmas Lubuk Buaya Kota Padang. Penelitian ini menjelaskan efektifitas penyelenggaraan e-puskesmas di Puskesmas Lubuk Buaya. Proses pengumpulan data dilakukan dengan observasi, wawancara, dan studi dokumentasi. Pengujian keabsahan datanya dilakukan dengan teknik triangulasi sumber.

Teknik analisis data dalam penelitian ini dilakukan secara kualitatif, melalui proses mencari data, mengatur wawancara dan mengumpulkan catatan di lapangan serta bahan - bahan lainnya yang sudah disusun dan dikumpulkan sehingga dapat menemukan hasil temuan. Data penelitian ini diolah dengan menggunakan analisis manual MDAP (Manual Data Analisis Procedure). Analisis data dalam penelitian ini dilakukan sepanjang proses penelitian.

\section{HASIL DAN PEMBAHASAN}

Berdasarkan temuan penelitian di atas, maka hasil penelitian untuk bagian ini dijelaskan 2 hal yang sesuai dengan rumusan masalah yaitu:

\section{Efektifitas Penyelenggaraan E- Puskesmas di Puskesmas Lubuk Buaya Kota Padang.}


Untuk mengukur keberhasilan atau kegagalan efektifitas dalam penerapan layanan e-Puskesmas di puskesmas Lubuk Buaya Kota Padang maka digunakan 3 (tiga) indikator efektifitas menurut Richard M.Steers (1985), yaitu: Pencapaian Tujuan, Integrasi, dan Adaptasi.

Indikator pertama yakni pencapaian tujuan.Yang dimaksud dengan indikator ini ialah keseluruhan upaya melalui dari sebuah proses sehingga pencapaian tujuan harus dipandang Oleh sebab itu, agar tercapai dalam proses pencapaian tujuan akhir diperlukan pentahapan. Berdasarkan hasil wawancara, akses aplikasi e-puskesmas hanya bisa oleh pihak puskesmas Lubuk Buaya Kota Padang.

Tampilan halaman depan aplikasi Epuskesmas terdapat logo Kota Padang, logo E-Puskesmas, dan kolom pengisian username dan password. Setelah login di dalam aplikasi E-Puskesmas terdapat berbagai menu dan sub menu yang disediakan guna untuk menghemat waktu dalam memberikan pelayanan kesehatan. Beberapa menu utama seperti, pendaftaran, pelayanan, pengelolaan, GIS (Geographic Information System, merupakan sistem informasi yang menginput data), serta laporan. Pada halaman pengisian biodata pasien pada e-puskesmas memiliki kelengkapan yang lengkap dan data keluhan penyakit pasien bisa terkirim ke bagian poli tertentu dengan cepat, sehingga pemeriksaan pasien bisa ditindak lanjuti di bidang tertentu secara cepat juga.

Aplikasi e-puskesmas terkoneksi langsung dengan rumah sakit rujukan di Kota Padang, sehingga data pasien yang berobat ditransfer pihak puskesmas Lubuk Buaya Kota Padang kepada rumah sakit rujukan lebih efektif dan keamanan data pasien juga terlindungi dari hal-hal yang tidak diinginkan. Berarti dengan demikian penyelenggaraan epuskesmas sesuai dengan pendapat Indrajit (2006) bahwa peran teknologi informasi dalam proses pemerintahan mampu meningkatkan kinerja yang terkait dengan aktifitas koordinasi, komunikasi dan termasuk aktifitas pelayanan.
Kedua, indikator integrasi pada aplikasi e-puskesmas disosialisasikan untuk pegawai puskesmas Lubuk Buaya Kota Padang saja. Namun, pasien juga diberitahu bahwa sistem online sudah berlaku sehingga proses administrasi berjalan lebih cepat.

Aplikasi e-puskesmas awalnya diperkenalkan oleh PT.Telkom kepada seluruh puskesmas di Indonesia, termasuk puskesmas Lubuk Buaya Kota Padang pada tahun 2016. Aplikasi ini disosialisasikan kepada puskesmas Lubuk Buaya Kota Padang dalam bentuk seminar sehingga bisa lebih efisien sosialisasi tersebut. Namun, sosialisasi ini hanya diperuntukkan pegawai puskesmas saja tidak untuk masyarakat”. Sosialisasi yang diperoleh puskesmas pada launching epuskesmas berupa seminar dengan PT. Telkom Indonesia bersama seluruh perwakilan puskesmas di Kota Padang. Aplikasi e-puskesmas hanya bisa diakses oleh pegawai puskesmas saja, tidak diperuntukkan untuk masyarakat umum. Sehingga komunikasi antara pegawai di puskesmas terjalin, baik dan jarang miskomunikasi, namun secara tidak langsung kami memberitahu seperti surat rujukan sudah bisa langsung dikirimkan ke rumah sakit tujuan tanpa harus pasien yang mengantar ke rumah sakit tujuan. Dengan demikian, aplikasi epuskesmas termasuk ke dalam tipe relasi Government to Employes yang dinyatakan oleh Indrajit (2002) bahwa aplikasi $e$ government juga dipergunakan untuk para pegawai negeri pemerintahan atau swasta yang bekerja di instansi bertujuan dalam meningkatkan kinerja dan kesejahteraan sebagai pelayan masyarakat.

Ketiga, indikator adaptasi yang merupakan ukuran kemampuan organisasi menyesuaikan pekerjaannya dengan wilayah kerjanya. Dalam penginputan data waktu yang dibutuhkan sekitar dua menit khusus untuk pasien awal, namun untuk pasien yang sudah ada dalam penginputan datanya kian terampil secara otomatis berhubung databasenya telah tersedia. Semestinya pendataan data dengan memakai apliksi epuskesmas lebih efisien Puskesmas tapi dalam hal ini masih ada pencatatan data secara 
manual, sehingga terjadi dua kali kerja. Seharusnya e-Puskesmas lebih efisien kalau di implementasikan sepenuhnya.

Setelah penerapan E-Puskesmas masih terdapat pencatatan yang dilakukan secara manual sehingga hal ini menjadi tidak efisien dan menghabiskan banyak waktu. Dengan demikian, aplikasi e-puskesmas masih butuh penyesuaian lebih lanjut untuk membantu pegawai dalam pengoperasiannya yang pada saat ini pegawai masih melakukan pelayanan manual bersamaan dengan penggunaan aplikasi e-puskesmas.

\section{Faktor Penghambat Efektifitas \\ Penyelenggaraan E-Puskesmas di Puskesmas Lubuk Buaya kota Padang}

Berdasarkan hasil wawancara pada saat penelitian, faktor utama yang menjadi penghambat adalah konektivitas. Jaringan internet seringkali terputus pada saat menginput data pasien yang berobat, sehingga mengganggu efektifitas aplikasi e-puskesmas saat memberikan pelayanan kesehatan dilakukan oleh pegawai puskesmas kepada masyarakat.

Penelitian ini serupa dengan penelitian yang sudah dilakukan oleh Arya Bagus Saputro (2017) yang berjudul "Pelaksanaan Layanan e-puskesmas di Puskesmas Ambacang Kecamatan Kuranji Kota Padang" hasil penelitian menjelaskan bahwa penerapan layanan e-puskesmas di Puskesmas Ambacang Kecamatan Kuranji Kota Padang tidak diterapkan dan terselenggara secara belum maksimal. Permasalahan utama ini disebabkan karena tingkat konektivitas internet tidak sesuai dengan kebutuhan.

Faktor penghambat lainnya yakni fitur. Fitur yang dimiliki aplikasi EPuskesmas memang banyak membantu pegawai puskesmas melaksanakan pekerjaannya melayani pasien, namun fitur laporan bulanan ternyata masih dinput secara manual pada setiap poli yang ada di puskesmas. Hal ini tentu kurang efisien, mengingat jumlah kunjungan pasien selama 30 (tiga puluh) setiap bulannya harus diinput manual ke dalam aplikasi e-puskesmas.

\section{KESIMPULAN}

Berdasarkan dari hasil penelitian yang dilakukan penulis tentang Efektifitas Penyelenggaraan E-Puskesmas di Puskesmas Puskesmas Lubuk Buaya Kota Padang dapat dijelaskan bahwa Penyelenggaraan EPuskesmas tersebut kurang efektif, hal ini dikarenakan masih terdapat faktor penghambat yaitu mengenai jaringan atau konektivitas yang tidak selalu bagus pada saat digunakan, terkadang terputus sehingga menyebabkan terhalangnya pelayanan kesehatan untuk pendataan pasien yang berobat ke puskesmas tersebut. Selain itu faktor penghambat lainnya terdapat pada fitur aplikasi E-Puskesmas yang masih kurang yaitu penginputan laporan bulanan pada setiap poli di Puskesmas tersebut harus diinput secara manual.

Dari indikator yang penulis gunakan untuk mengukur efektifitas penyelenggaraan e-puskesmas di Puskesmas Lubuk Buaya Kota Padang masih belum tercapai sepenuhnya, yaitu :

a. Pencapaian Tujuan

Aplikasi e-puskesmas ini bertujuan untuk meningkatkan kualitas puskesmas sesuai prinsip akuntabilitas, dapat dipercaya dan bertanggungjawab. Tujuan penyelenggaraan e-puskesmas ini sudah tercapai, namun belum maksimal sepenuhnya, hal ini disebabkan masih terdapat dari sebagian pasien yang belum mengetahui adanya aplikasi e-puskesmas tersebut.

b. Integritas

Aplikasi e-puskesmas $\begin{array}{r}\text { hanya } \\ \text { kepada }\end{array}$
disosialisasikan
puskesmas saja dan tidak disosialisasikan
kepada masyarakat. Meskipun aplikasi
tersebut hanya dipakai oleh pegawai
puskesmas, seharusnya aplikasi ini
disosialisasikan juga kepada masyarakat,
agar masyarakat mengetahui
perkembangan sistem informasi kesehatan.
Adaptasi
Puskesmas Lubuk Buaya Kota
Padang sudah cukup mampu
menyesuaikan kegiatan pelayanan
kesehatan menggunakan e-puskesmas,


namun fitur laporan bulanan pada aplikasi tersebut ternyata penginputannya setiap bulan masih dilakukan secara manual.

\section{SARAN}

Berdasarkan hasil dan pembahasan yang telah penulis lakukan ada kendala yang ditemukan di lapangan, sehingga penulis memberikan saran sebagai berikut:

1. Diharapkan kepada pihak Puskesmas Lubuk Buaya untuk lebih mengoptimalkan penyelenggaraan epuskesmas agar efektif dalam melayani masyarakat yang berobat.

2. Aplikasi E-puskesmas sebaiknya perlu ditingkatkan fitur-fitur aplikasinnya oleh pihak PT.Telkom, agar terbantu pegawai puskesmas dalam melayani masyarakat yang berobat.

\section{DAFTAR PUSTAKA}

Handayaningrat, Soewarno.(1994). Pengantar Studi Ilmu Administrasi dan Manajemen. Jakarta : CV Haji Masagung.

Harsiti, Tedi, Purnamasari. M, dan Dwiyanto,S. (2016). Rancang Bangun Aplikasi E- Health untuk Peningkatan Pelayanan Kesehatan Pada Puskesmas Kibin. Jurnal Sistem Informasi. 15-18.

Indra,Wijaya dan Adam, Ibrahim. (2010. Teori, Perilaku, dan Budaya Organisasi. Bandung: Refika.

Indrajit, Richardus. Eko. (2006). Electronic Government : Strategi Pembangunan dan Pengembangan Sistem Pelayanan Berbasis Teknologi Digital . Jakarta: Andi Offset.

Irawan, B. (2013). Studi Analisis Konsep EGovernment: Sebuah Paradigma Baru dalam Pelayanan Publik. Jurnal Paradigma.174-201.

Kristianti, E. (2013). E-Health di Indonesia. Jurnal Teknik dan Ilmu Komputer. 167- 171.

Nur, Mas Ammah. 2017. Penerapan Layanan Electronic Health (E-Health) di Puskesmas Peneleh Kecamatan
Genteng Kota Surabaya. Skripsi. UNESA. Surabaya.

Rosadi, S.D. (2016). Implikasi Penerapan Program E- Health dihubungkan dengan Perlindungan Data Pribadi. Jurnal Arena Hukum.403-420.

Satriadi. (2019). Penerapan E-Puskesmas Pada Puskesmas Tanjung Pinang. Skripsi. STIE Pembangunan Tanjung Pinang. Tanjung Pinang.

Steers, Richard M, Terj.(1985). Magdalena Jamin, Efektifitas Organisasi. Jakarta: Erlangga.

Sutrisno, Edy. (2010). Budaya Organisasi. Jakarta: Kencana. 